\title{
Pentagon plays havoc at optical conference
}

\section{Washington}

THE US Department of Defense (DoD) caused severe disruption at a technical symposium of the Society of Photo-Optical Instrumentation Engineers (SPIE) in Virginia last week when it withdrew at a few days' notice some 50 papers previously scheduled for presentation. The titles of the papers and some of the abstracts had been cleared for publication by DoD, but many of the texts were later found to contain either classified information or information subject to export regulations.

Eventually, most of the papers were presented (after some censorship) in a new type of "export-controlled" session, attendance at which required US nationals to certify that they would keep technical information confidential and which required foreign nationals to be sponsored by their embassies. Twelve of the 50 papers were declared classified and were not presented.

DoD last year declared that it would rely only on classification to restrict publication of fundamental research carried out on university campuses. As universities do not generally carry out classified research on campus, this seemed like a guarantee not to interfere with academic work. But the papers restricted at the SPIE conference were based on research by private contractors receiving DoD funds in category 6.3 , which covers research that is potentially militarily sensitive and classifiable. Research in category 6.3 is not generally considered to be "fundamental", but none of that affected at the SPIE conference had actually been classified. Private research contractors, in contrast to universities, do accept contract clauses requiring researchers to submit papers to DoD for prepublication scrutiny - effectively a licence for DoD to prevent dissemination of the information should it so choose.

DoD says that all of the 50 affected papers would have had to be suppressed totally, by invoking prepublication review clauses, but for a new authority in the 1984 Defense Authorisation Act, under which DoD could allow most of the papers to be given, but on condition that those present would agree to the confidentiality requirements of export-controlled sessions.

Conference organizers say that no foreign national wanting to attend one of the two export-controlled sessions was denied access, but a number of them at the conference decided, for various reasons, not to seek admission to the controlled sessions, which dealt with synthetic aperture optics and wavefront sensors. Both areas have applications to astronomy as well as to weapons design: adaptive optics may be used to "untwinkle" stars in large telescopes, while synthetic aperture interferometry may allow many optical telescopes to be combined.

In the 1984 Defense Authorisation Act, DoD was given new authority to deny public access to unclassified technical data in its control that are judged to contain critical technology with military or space applications and which cannot be exported without restriction under Export Administrations Regulations. Previously, the department had no authority to withhold such technical information when faced with a request under the Freedom of Information Act.

It is now DoD policy to oppose the open distribution at conferences of unclassified technical data subject to export control. But DoD is also authorized to make such data available to those who are prepared to guarantee its confidentiality, which mechanism DoD brought into play for the first time at the SPIE conference. The exemption was granted by Congress in response to the concern of small defence contractors, which feared that they would otherwise be denied data necessary for them to bid competitively for DoD contracts.

The American Civil Liberties Union and the American Association for the Advancement of Science expressed concern last week that DoD had used a legal authority applying to DoD-controlled data to restrict public access to research material still the property of the contractors. DoD's explanation is that it still relies on contractual restraints to prevent open publication, and that only the exemption of those guaranteeing confidentiality was derived from the 1984 Authorisation Act. But, paradoxically, the exemption mechanism that DoD brought into play last week could in practice allow DoD to impose tighter control through contract mechanisms. Many allied countries fear that the United States is tempted to restrict foreign access to cutting-edge technology because of its commercial rather than its military importance.

Much of the very visible annoyance at last week's conference was due to the lateness of DoD's intervention. Sessions were being rearranged from one day to the next. But DoD says this was a practice run at making some export- controlled data available in unclassified but restricted sessions, and says that the lateness was due to the failure of another scheme which had been proposed - to have two entirely classified sessions running in parallel with the regular conference. Only one classified session was in fact held. Tim Beardsley

\section{Accelerator scrutiny in prospect}

\section{Washington}

THE US House of Representatives Science and Technology Committee has warned that it intends to treat particle physicists sceptically when considering construction of the proposed Superconducting Super Collider (SSC).

In approving the administration's

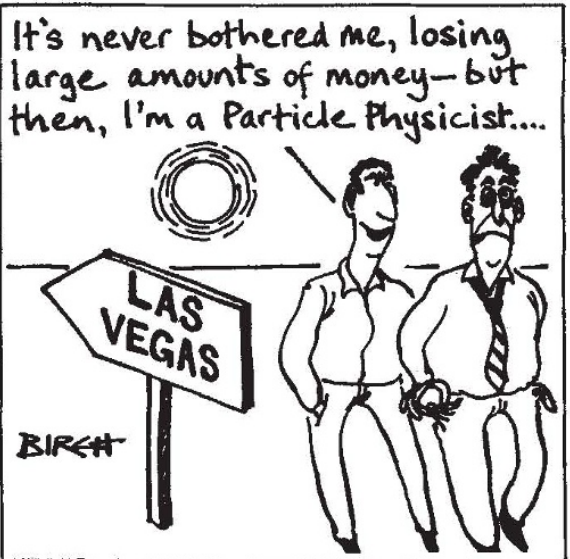

request of $\$ 20$ million for continued research and development on the accelerator project, much less than the $\$ 60$ million that the Department of Energy (DoE) had asked for, the committee said that it doubted whether DoE's goal of starting construction by 1988 could be met.
Still smarting over its experience with ISABELLE, Brookhaven National Laboratory's \$200 million fiasco, the committee said it would not even consider a proposal for SSC until DoE could prove that the superconducting magnets will function as planned for the advertised price. ISABELLE, delayed for years, was abandoned in $\mathbf{1 9 8 3}$ after unexpected problems in design of the superconducting magnets. Although the problems were eventually ironed out, events in physics had in the meanwhile made ISABELLE obsolete, but not before a 21/4-mile-long tunnel, control room, experimental areas and magnet production facilities had been built.

Optimistic projections put the cost of the SSC magnets at 15 per cent less per unit of length than those now operating at Fermilab; at $\$ \mathbf{5 , 0 0 0}$ per metre and assuming an $80-\mathrm{km}$ ring, that works out at $\$ 400$ million for the magnets alone. The current estimate for the total cost of SSC is still $\$ \mathbf{\$ 3 , 0 0 0}$ million, not including detectors, research and development and allowance for inflation.

Leon Lederman, director of Fermilab, said that previous proposals had been approved by congressional committees almost "by return mail". "We're bearing the cross of ISABELLE", he said. Stephen Budiansky 